\title{
Experimental and computational investigation of a new solar inte- grated collector storage system
}

\section{Domenico Borello $^{\mathrm{a}}$, Alessandro Corsini, Giovanni Delibra ${ }^{\mathrm{a}}$, Sara Evangelisti ${ }^{\mathrm{b}}$ and Andrea Micangeli $^{\mathrm{b}}$}

${ }^{a}$ Dipartimento di Ingegneria Meccanica e Aerospaziale, Sapienza Università di Roma, Via Eudossiana 18, 00184 Roma, Italy

${ }^{b}$ CIRPS - Centro Interuniversitario di Ricerca Per lo Sviluppo sostenibile, Sapienza Università di Roma, Piazza San Pietro in Vincoli 10, 00184 Roma, Italy

\begin{abstract}
We present a combined experimental-numerical analysis of an innovative solar thermal device to be used as an integrated collector storage (ICS) system providing domestic hot water (up to $50^{\circ}-60^{\circ} \mathrm{C}$ ). In this equipment the collector acts also as a storage unit, without requiring an external vessel. Due to its simple configuration, the ICS was successfully used in several circumstances, especially in extreme situations such as in post-earthquake tent cities or to reach remote users in Africa.

In order to assess the efficiency of this collector, we measured the draw-off curve (that is the value of the mean temperature of the water discharging from the tap while cold water is entrained in the collector). In the present configuration the draw-off is not completely optimised and a more detailed analysis has been carried out in order to investigate the mixing of cold and hot water in the solar collector during the discharge phase.

A series of thermocouples was placed in selected positions around the shield of the collector to investigate the evolution of the near wall temperature.

Furthermore, a numerical analysis based on Large-Eddy Simulation (LES) of the mixing process inside the collector was carried out using an open source, in-house, finite-volume computational code. This analysis is in progress and the complete results discussion will be provided in the final paper

The analysis of the experimental and computational results showed that the present configuration is not optimal and that improvements could be obtained improving the collector inflow configuration.
\end{abstract}

\section{Keywords}

Integrated solar collector, draw-off curve, temperature measurement, simulation of mixing process, large-eddy simulation. 


\section{Introduction}

Solar Thermal Technologies represents an efficient and cost effective solution for collecting solar energy received on the ground. In particular the production of domestic hot water constitutes a particularly interesting application of solar energy due to the very simple configuration to be implemented and the general good efficiency of the equipments.

In Europe the solar thermal market had a significant increase in recent years due to several factors: the decision to reduce dependence on conventional fuels increasing the use of Renewable Energy Sources (RES), the new provisions forcing to introduce solar thermal systems in new or renewed buildings in EU, the wide availability of RES and their low environmental impact. Therefore solar heating represents today a well established and reliable technology, potentially able to achieve high levels of energy production [1].

Solar energy collector is special kind of heat exchanger which absorbs the incoming solar radiation, converts it into heat, and transfers this heat to a fluid (usually air, water, or oil) flowing through it and then uses it for a variety of applications [2].

Solar thermal systems in which the same device serves as a collector as well as for storage have an obvious advantage over the conventional systems with separate units. Such systems are referred to as integrated collector-storage systems (ICS).

In recent years several configurations of solar integrated collector storage systems for hot water have been tested. Most of such configurations are based on the use of a storage water tanks collecting the hot water flowing from the collector for domestic and industrial usages. Usually the water tank is cuboid in shape and different configurations were considered for heating: water can be heated at the top surface and covered with opaque insulation on all other sides, or the water tank can have transparent insulation on all its external surfaces. Recently a simulated well-stratified tank [3] was also considered for insulated water heaters.

The ICS system analysed in the present paper is an innovative device developed by Dipartimento di Ingegneria Meccanica e Aerospaziale, Sapienza Università di Roma [4,5]. It is a one piece, closed-circuit system and it works without pumps or electrical devices. The storage unit is composed by the internal pipes. The panel absorbs the solar energy and the water within the collector rises up for convection moving towards the outlet pipe and reaching the domestic net when hot water is required. Integrated collector-storage systems are simple, but they are characterized by relatively low thermal conversion efficiency.

For these devices efficiency is strongly related not only to their capability to capture the solar radiation, but also to their attitude to supply hot water during the discharge phase (draw-off) with a constant temperature. On the other hand, the cold water entrained into the collector mixes with the hot fluid and this progressively reduces the temperature of the water flowing through the tap. Presently this aspect is not optimal leading to a strong reduction of the water temperature after a very short period (more than $50 \%$ when $50 \%$ of the hot water filling the collector was discharged). In optimal conditions the fresh water filling the collector should act as a sort of piston pushing the hot water out and maintaining the fluid temperature to a maximum during all the discharge phase.

To increase the performance of this kind of ICS system both experimental and computational analysis have to be carried out. Experimental campaign can give a clear indication of the real behaviour of the equipment measuring the main discharge flow characteristics. On the other hand, numerical simulations allows to analyse in detail the thermal field in the collector and therefore it has to be considered essential to detect possible improvements of the present configuration. In particular LES in fact can give an extraordinary insight of the mixing process inside the ICS allowing to understand the mechanism inside the tank and suggesting possible ways to optimize the geometry and the position of the inlet and outlet pipes. Even if similar studies were conducted on heat exchange cases that in principle are physically similar to the present study but not on ICS applications. It is worth to consider that in the present case LES computations are not extremely expensive as the Re number is sufficiently low. In the follow- 
ing paragraphs the experimental set-up and the measurement campaign are described. Then a LES analysis of the thermal flow field evolving in the collector is presented. Conclusion will close the present work.

\section{The experimental apparatus}

\subsection{The new ICS prototype}

The prototype of the ICS here presented was built in the Solar Energy laboratory - Hydrogen Centre of CIRPS, Sapienza Università di Roma [6]. It is composed by 4 pipes of $120 \mathrm{~mm}$ diameter each with an internal total storage capacity of about 901 (22,5 1 for each pipe). It has a specific storage capacity of about $601 / \mathrm{m}^{2}$, while in a plate solar collector this ratio is equal to 1$21 / \mathrm{m}^{2}$. The absorbing plates are constituted by the pipes themselves and the working fluid of the system is domestic water. In fact the collector is directly connected with the water net and no other components are needed to heat the water.

The main characteristics of the collector are showed in Table 1.

Table 1 - Characteristics of the ICS prototype

\begin{tabular}{|l|c|c|}
\hline Characteristic & Unit & Average Value \\
\hline Capture surface & $\mathrm{m}^{2}$ & 1.5 \\
\hline Projected surface & $\mathrm{m}^{2}$ & 0.96 \\
\hline Pipe length & $\mathrm{m}$ & 2 \\
\hline Pipe diameter & $\mathrm{m}$ & 0.12 \\
\hline Water content & 1 & 90.42 \\
\hline Weight (no water) & $\mathrm{kg}$ & 38 \\
\hline Maximum operating pressure & $\mathrm{bar}$ & 3 \\
\hline
\end{tabular}

In Table 2 the components used to manufacture are shown.

Table 2 - ICS prototype's materials

\begin{tabular}{|l|l|l|}
\hline Description & Material & Main Characteristics \\
\hline $\begin{array}{l}\text { Transparent } \\
\text { covering }\end{array}$ & alveolar polycarbonate & $\begin{array}{l}\text { Transmission coefficient: } 0.726 ; \\
\text { thickness: } 8 \mathrm{~mm}\end{array}$ \\
\hline Pipe & Stainless steel 316 L & $\begin{array}{l}\text { Thermal conductibility } 16.3[\mathrm{~W} / \mathrm{mK}] \\
\text { Thermal dilatation } 0.000016\left[\mathrm{~K}^{-1}\right]\end{array}$ \\
\hline $\begin{array}{l}\text { Lateral } \\
\text { insulation }\end{array}$ & $\begin{array}{l}\text { Polyurethane layer; } \\
\text { Closed Cell Elastomeric } \\
- \text { aluminium foil }\end{array}$ & $\begin{array}{l}\text { Thermal conductibility } 0.040[\mathrm{~W} / \mathrm{mK}] \\
\text { Thermal conductibility } 0.027[\mathrm{~W} / \mathrm{mK}]\end{array}$ \\
\hline Structure & Galvanized steel & Thermal conductibility $18[\mathrm{~W} / \mathrm{mK}]$ \\
\hline
\end{tabular}

The developed ICS prototype is shown in Figure 1.

The stainless steel pipes are connected in a series and the pipes are painted with a black high temperature paint.

The thermal insulation has the function to minimize the heat losses for conduction on the sides and on the back of the pipes. A transparent plastic cover made of closed cell polycarbonate assures an optimum thermal insulation with a good transparency.

The inlet and outlet pipes of the collector have a $16 \mathrm{~mm}$ diameter, and they are welded in the middle of the pipe. A ball valve has been placed on the inlet and outlet pipe to close the system. 


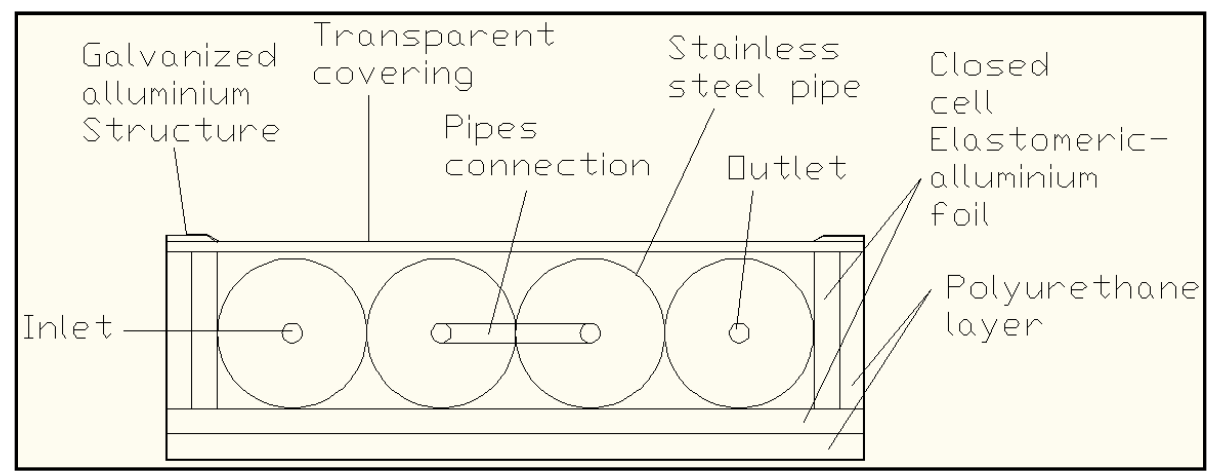

Figure 1 - Sketch of the ICS prototype

\subsection{The test bed set-up}

To investigate the discharge process a test bed has been set up in the laboratory. As the pipes are connected in series, only one was instrumented. The inlet and outlet pipes were instrumented as well and the main pipe was isolated with a polyurethane layer and an elastomericaluminium foil in order to reproduce the same conditions of the whole collector.

A series of $8 \mathrm{~J}$-type thermocouples have been placed to measure the temperature during the thermal energy storage phase and during discharge. The accuracy of the thermocouples was $\pm 1.5^{\circ} \mathrm{C}$ and the acquisition frequency was $0.88 \mathrm{~Hz}$. Solar radiation fluctuations have been followed by a pyranometer system with an accuracy of $\pm 10 \mu \mathrm{V} /\left(\mathrm{W} / \mathrm{m}^{2}\right)$. The 8 thermocouples $(7$ have been used to monitor the pipe and one for the ambient temperature) and the pyranometer have been connected, through a Thermocouple and RTD modules, with a National Instrument Field Point with Ethernet connection and connected to a data processing (PC) through LabVIEW, as showed in Figure 2.

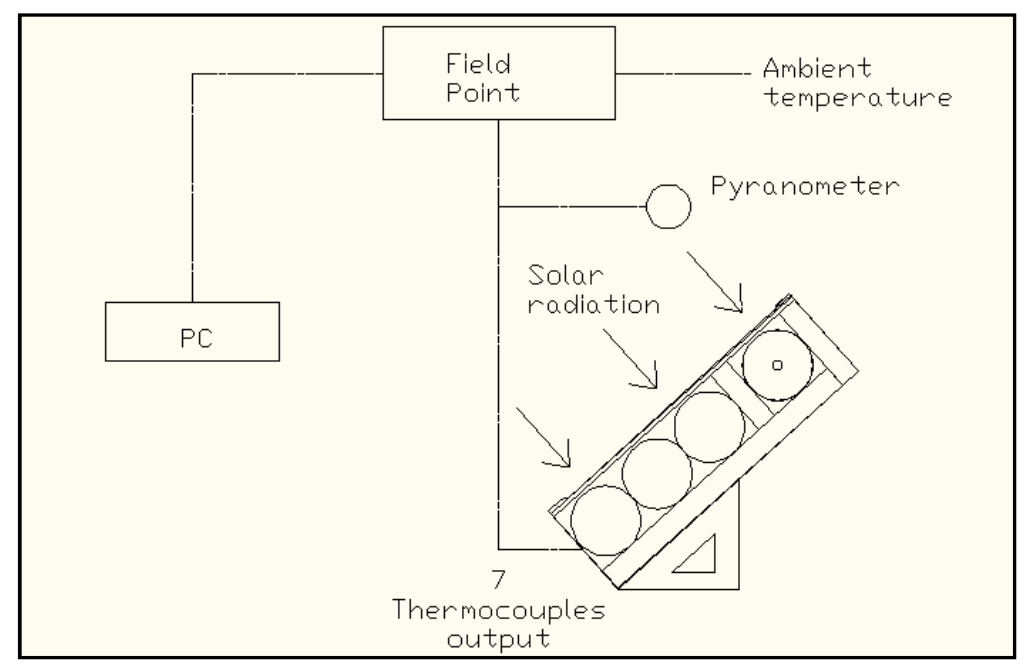

Figure 2 - Experimental device

During the charge phase, the pipe has been placed in vertical position in order to be completely filled with water and to eliminate the air. Then it has been placed on its supports, with a tilt of 42 degrees.

Figure 3 shows the position of the thermocouples on the pipe. Three measurement campaigns were carried out changing the thermocouples circumferential positions as shown in Figure 3 (positions A, B and C). 


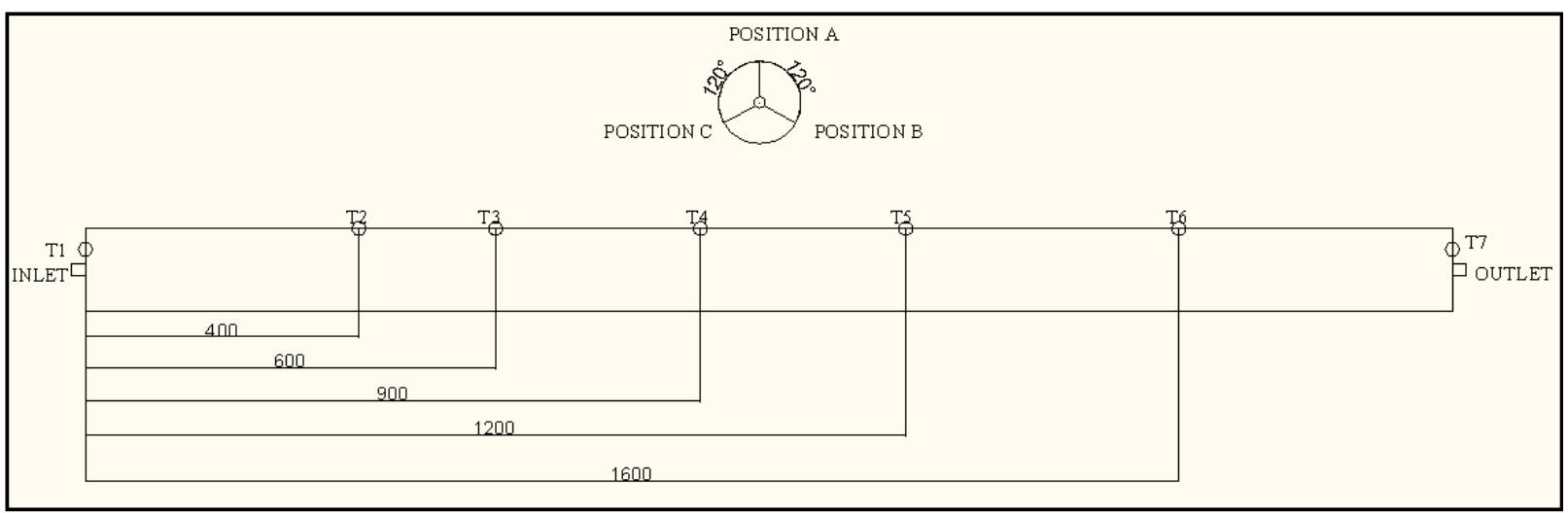

Figure 3 - Thermocouples placement

\section{Experimental results}

To characterise the discharge phase different draw-off tests have been carried out, monitoring the temperatures measured by the 8 thermocouples and the pyranometer. Before starting the test, the pipe was filled with the water coming from the net in order to have the same temperature value in the system. Then the collector has been exposed to the solar radiation to store up the thermal energy. This phase requires several hours depending on the weather condition of the test day. The signals coming from the thermocouples were monitored and elaborated during the discharging phase and the domestic water was discharged until the inlet temperature was reached the same value of the outlet one $\pm 1^{\circ} \mathrm{C}$.
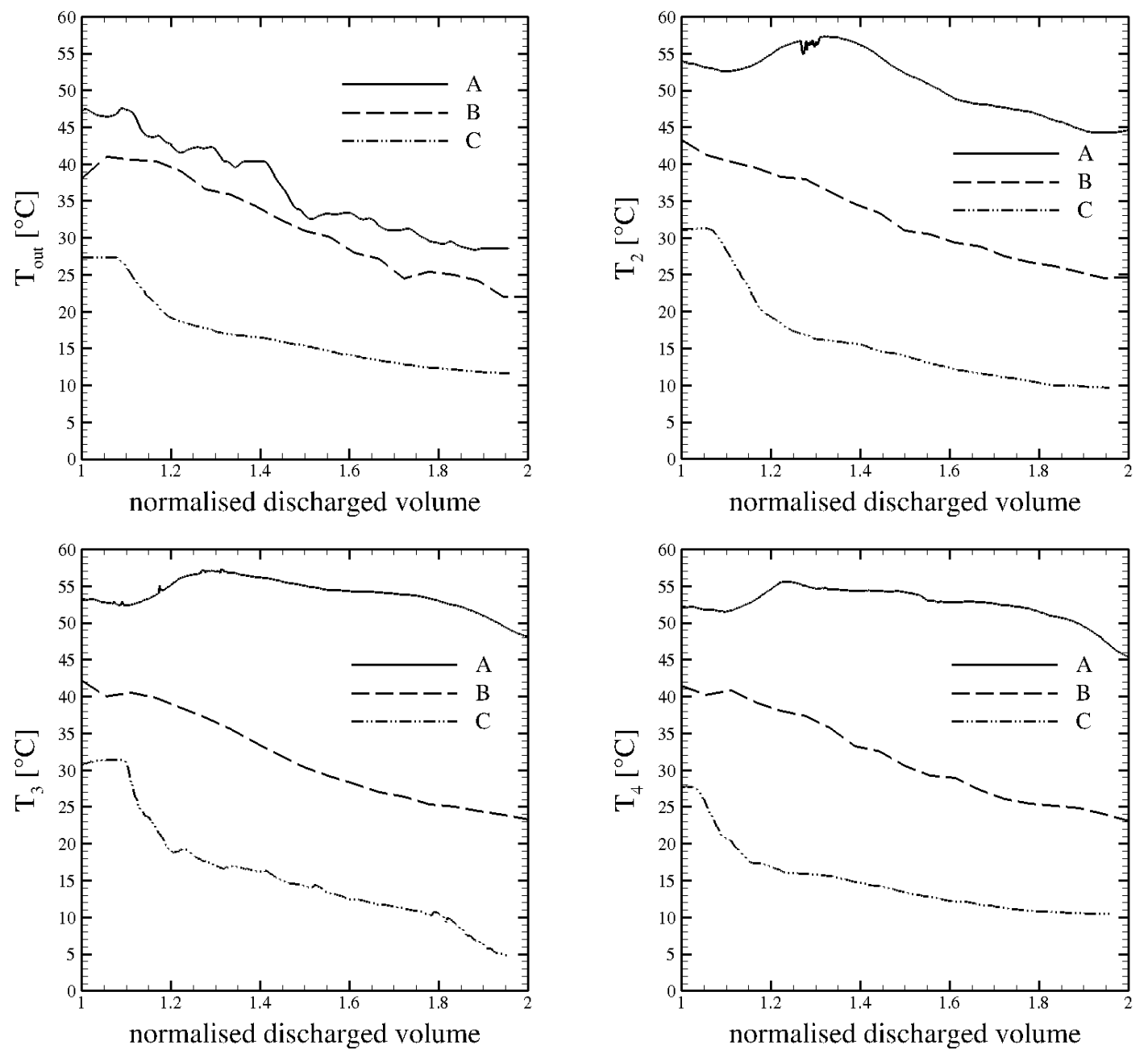

Figure 4-Draw-off temperatures in the outlet section and in positions 2, 3, 4 (Figure 3) 
A set of normalized draw-off curves - i.e. the temperature variation depending as function of the discharged volume - was analysed for each test. Figure 4 shows the draw-off profile normalized with respect to the ICS prototype volume in the three different positions.

Results show that with a fairly sunny day in December at the latitude of Civitavecchia (Italy), the collector can heat water up to a temperature of more than $45^{\circ} \mathrm{C}$. The three tests showed in Figure 4 were carried out with different environmental conditions, as showed in Table 3 . This brings to different inlet and outlet temperatures for the three positions at the beginning of the draw-off tests. For the position A, where the thermocouples are placed at the top of the pipe, even after the discharge phase the temperature of the collector was about $30^{\circ} \mathrm{C}$, and it was possible to spill a water volume of 1.5 times the volume of the system at a temperature of more than $40^{\circ} \mathrm{C}$. The lower the environmental temperature, the lower is the outlet temperature of the water. Furthermore, Figure 4 shows that the temperature measured by the thermocouples are in phase (i.e. the same value along the shield) in any moment of the discharge process for all the atmospheric conditions.

In Table 3 it is possible to see that the water in the ICS prototype can rise up to about $20^{\circ} \mathrm{C}$ with respect to $\mathrm{T}_{\text {env }}$.

Table 3 - Average value on the thermocouples

\begin{tabular}{|c|c|c|c|}
\hline & A & B & C \\
\hline Thermal radiation $\left[\mathbf{W} / \mathbf{m}^{2}\right]$ & 684 & 631 & 700 \\
\hline $\mathbf{T}_{\text {out }}\left[{ }^{\circ} \mathbf{C}\right]$ & 43 & 36 & 20 \\
\hline $\mathbf{T}_{\text {env }}\left[{ }^{\circ} \mathbf{C}\right]$ & 21 & 18 & 8 \\
\hline
\end{tabular}

\section{Numerical simulations}

From the experimental analysis it was possible to argue that improvements of the ICS configuration are desirable. Having in mind that the strength of this collector is based on its simplicity, an improvement of the collector efficiency should be obtained by changing the inflow or outflow configuration maintaining the structure of the ICS unchanged.

It is then fundamental to investigate the mixing process inside the collector to detect the turbulent structure arising in order to obtain useful clues for improving the collector design.

We assume here that the collector is completely filled of water, no thermal stratification of the fluid is present and that the pipe shield has a constant temperature of $60{ }^{\circ} \mathrm{C}$.
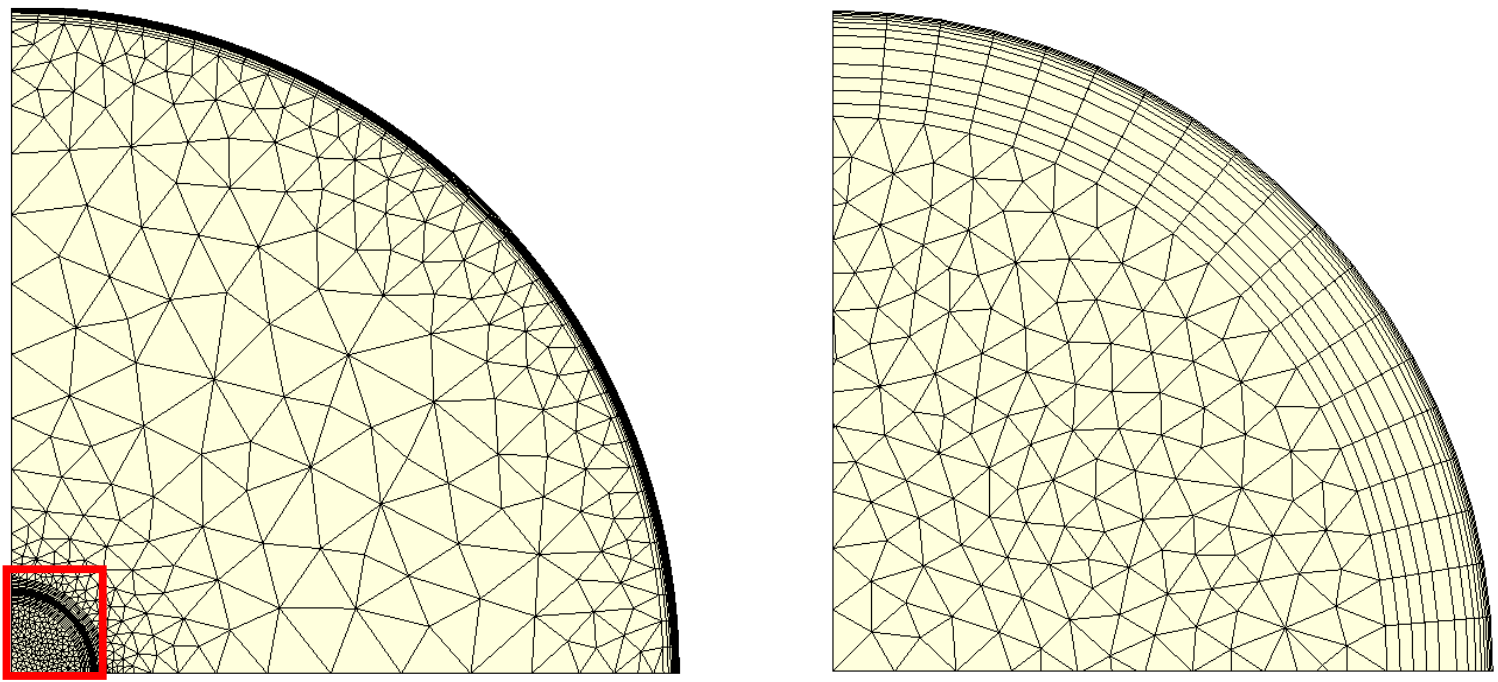

Figure 5 - Computational grid: 90 degrees of the cross- section are shown. Left: complete cross-section. Right: the exit pipe (highlighted in the red square on the left picture). 
Numerical simulations were performed using an open-source in-house Finite Volume code $2^{\text {nd }}$ order accurate in time and space on a parallel cluster [7-8]. The code was successfully tested in a series of calibration and industrial test case carrying out LES, URANS and hybrid LES/RANS simulations [8-11]. The computational domain reproduces one of the pipes of the ICS and was discretised using about $2.2 \mathrm{M}$ cells; hexahedral cells were used to discretise a layer along the solid walls whereas the rest of the domain was meshed using triangular prisms; the cell pattern is extruded in streamwise direction (z) so in Figure 5 just a cross-section on the xy plane is shown.

Numerical computations were carried out with an incompressible dynamic Smagorinsky LES [12] and treating temperature as a passive scalar transported by the velocity field. Reynolds number (based on the inlet pipe diameter $d$, inflow bulk velocity $U_{b u l k}$ and water viscosity) is equal to 19,258 . The clustering of the mesh is sufficient to ensure $y^{+}<1.0$ everywhere in the cells row closer to the solid walls $\left(y^{+} \sim 0.3\right.$ around the main pipe of the ICS $)$. The simulations were performed in non-dimensional time and length units using $d, t=d / U_{\text {bulk }}$ and using $\Delta \mathrm{T}=\mathrm{T}_{0^{-}}$ $\mathrm{T}_{\text {in }}$ as reference value for Temperature. In order to simulate the draw-off process, the simulation were performed starting from an initial condition of still, hot fluid inside the ICS (i.e. velocity components and turbulent viscosity were set to zero everywhere in the domain, pressure was assumed constant, with non-dimensional temperature $\mathrm{T}^{*}=1.0$ ). As boundary conditions we imposed: in inflow a steady mass flow with non dimensional temperature $\mathrm{T}^{*}{ }_{\mathrm{in}}=0.0$ and bulk velocity equal to 0.76 ; no-slip, fixed temperature $\mathrm{T}^{*}=1.0$ on the solid surfaces; convective conditions at the outlet. For stability reasons, the first 10 time units (corresponding to the time needed for the water to move from the inlet to $1 \%$ of the length of the ICS $L$ ) were simulated using a laminar solver in order to initialise the flow field and simulate the pressure unbalance generated from the opening of the tap at the outlet. After 10 time units the Smagorinsky model was switched on imposing a constant value of $v_{\mathrm{SGS}} / v=5$ at the inlet.

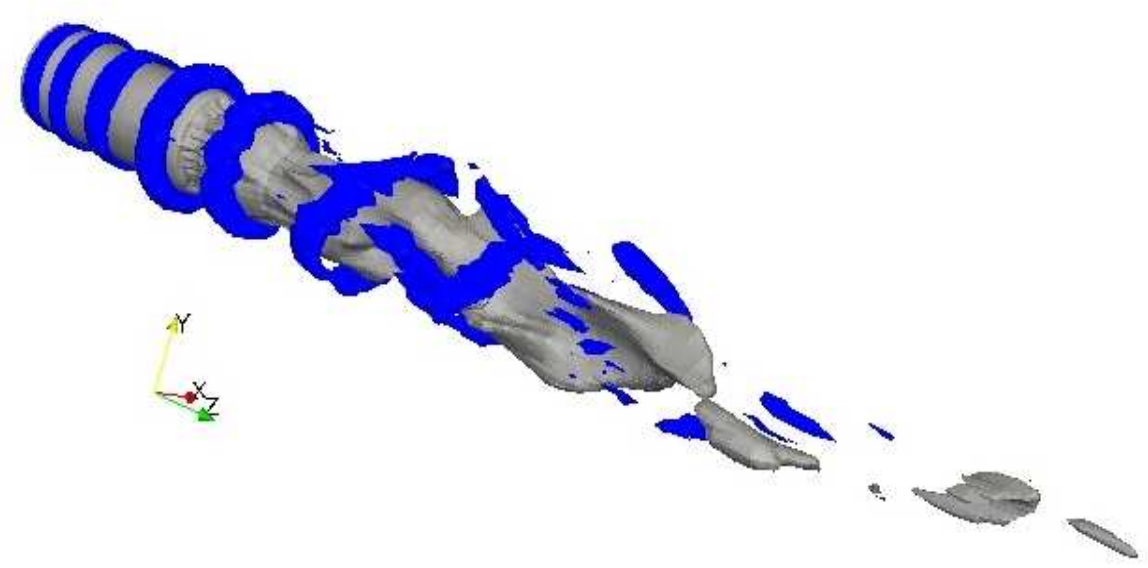

Figure 6 - LES of a confined jet - Isosurfaces of $Q=3$ (dark blue lines) and $w=0.76$

In Figure 6 the isosurface of Q factor in the pipe is shown together with an isosurface of axial velocity $w$. The $\mathrm{Q}$ criterion [referenza all'articolo del francese] represents a very effective way to detect the evolution of the vortical structures. It is possible to see that in the first stages of the jet development (up to 5\% of the pipe lenght), the Q shows a very regular, steady, toroidal structure. Moving donwstream this structures becomes irregular, unsteady and the torioidal structure change the direction of its axis as shown in several studies before -see e.g. [13].

In Figure 7 a snapshot of the instantaneous velocity components and temperature at $t^{*}=250$ is shown. In the picture a section corresponding to $\sim 40 \%$ of the length of the pipe is represented. As expected, the cold water jet breaks up after few inflow diameter and it generates strongly 
unsteady structures mixing with the hot fluid and reducing the fluid temperature. Furthermore an extended region of stagnant hot flow remains near the inflow region and around the jet.

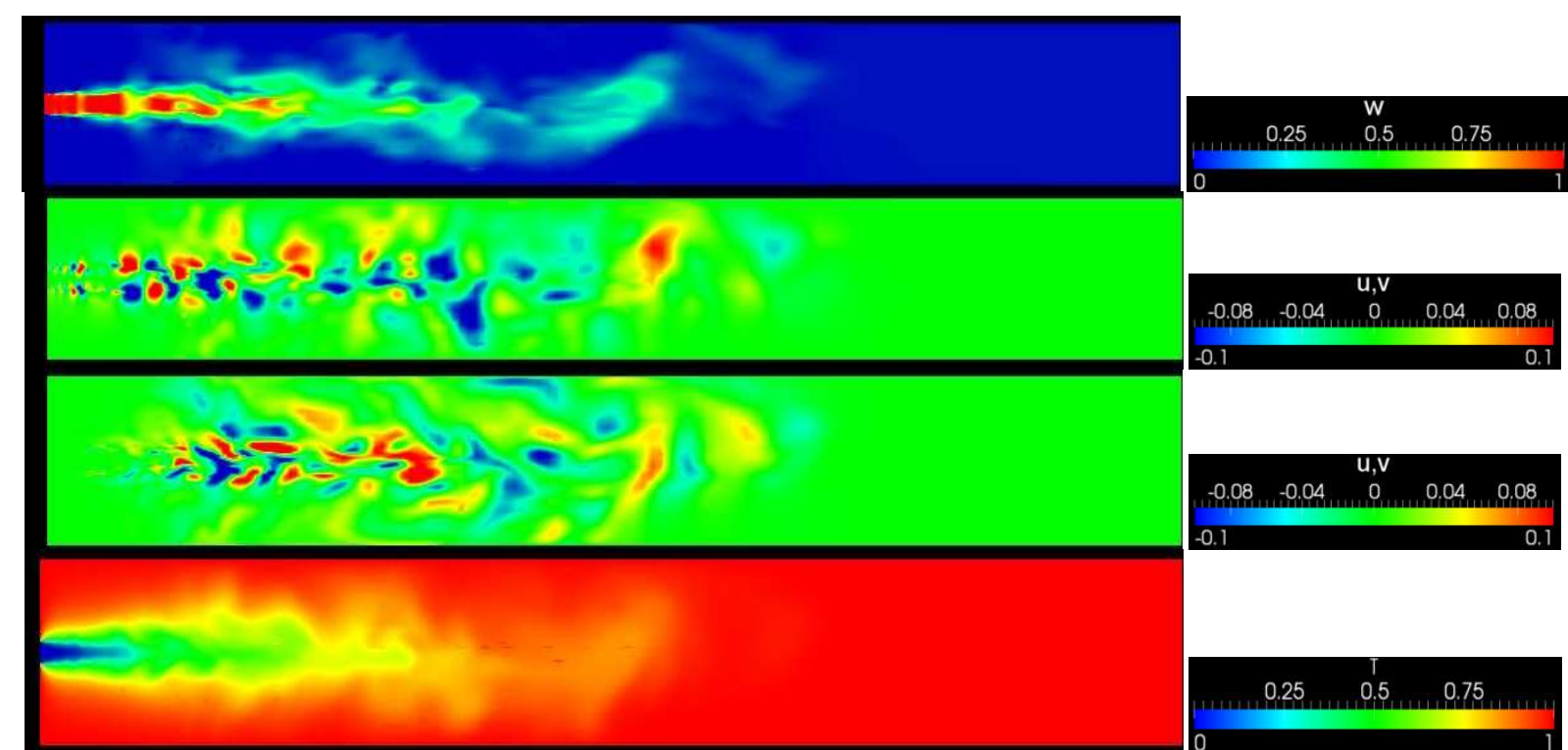

Figure 7 - From top: snapshot of instantaneous streamwise velocity component (w), spanwise components ( $u$ and $v$ ), and temperature (T) on the $\mathrm{YZ}$ plane; only $40 \%$ of the ICS chamber length $L$ is shown.

In Figure 8 and Figure 9 the development of the jet structure in three successive time step is depicted. It is possible to see that the inflow region up to $3 \%$ of the collector length $L$ and corresponding roughly to the perturbed region shown in Figure 8 remains quite steady and unperturbed confirming the hypothesis about the presence of a region of stagnant unperturbed flow. On the other hand the instabilities due to the oscillations in the pressure field are responsible for the later unsteady behaviour that is partially visible in the cross-section at $6 \%$ of $L$ and clearly recognizable in the following regions. These oscillations cause the jet to warp and spread losing momentum as it enters the chamber. At about $10 \%$ of $L$ the core of the vortex has almost halved the velocity and spread towards the wall of the main chamber conspicuously promoting a strong mixing of hot and cold flow in the central region, yet leaving almost undisturbed the temperature field in the first portion of the chamber.

Even if the computations are still in act, it is possible to draw some conclusions regarding the geometrical setting of the solar collector. We argue that the present configuration, even if very simple and easy to build up is not optimal and it has to be further investigated. A possible improvement could be obtained by changing the position of the inlet and outlet pipes, and to insert some type of swirl in the inflow jet in order to enhance the distribution of temperature inside the collector leading to a more appropriate draw-off temperature.

\section{Conclusions}

A combined experimental-numerical analysis of a prototype of an integrated solar collector was here presented. The collector was disegned for being used in emergency situation or for feeding remote users. Then a very simple configuration was adopted.

The experimental analysis demonstrates that in the present configuration the ISC has a reasonable performance in supplying hot water during the discharge phase.

However the analysis of the draw-off curve, the measurement of the temperature variation on the shield of the collector and the LES analysis of the mixing between hot and cold water inside 
the collector during the discharge phase indicate that improvements in the efficiency of the ISC can be probably obtained by changing the setting of the inlet and/or outlet pipes.

In the final paper the present analysis will be concluded indicating the most promising solutions to be adopted to improve the overall performance of the collector.

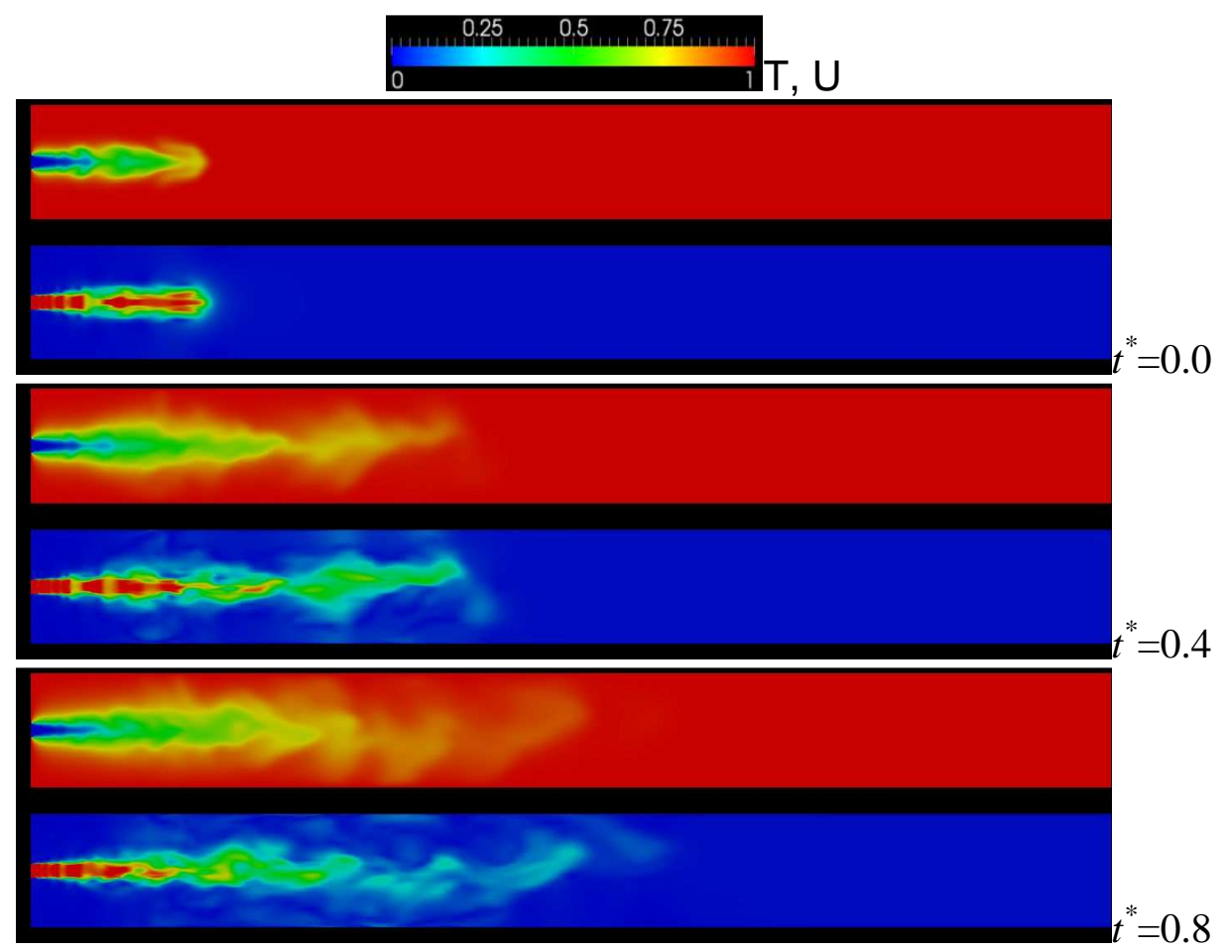

Figure 8 - Longitudinal view of the temperature (top) and velocity magnitude (bottom) fields in three successive time steps.
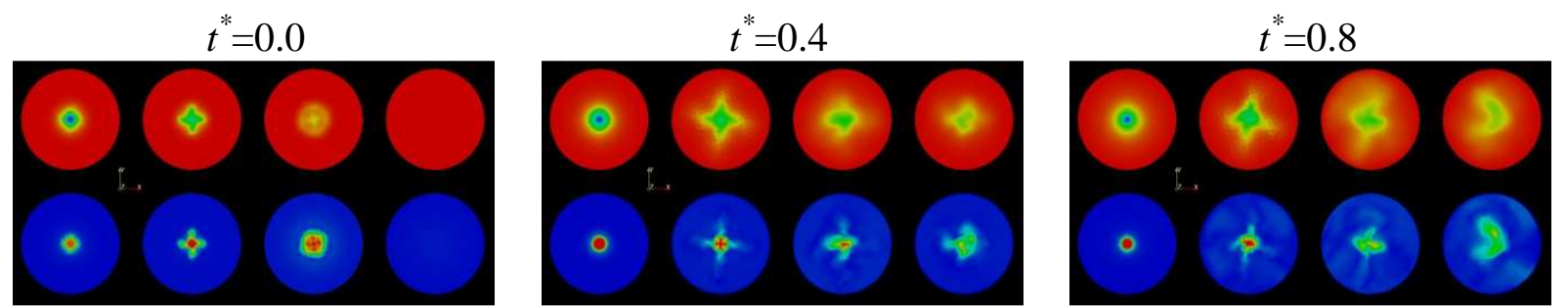

Figure 9 - Cross-flow plots of the temperature (top) and velocity magnitude (bottom) fields in three successive time steps. In each picture sections are taken (from left to right) at 3, 6, 9 and $12 \%$ of the collector length $L$.

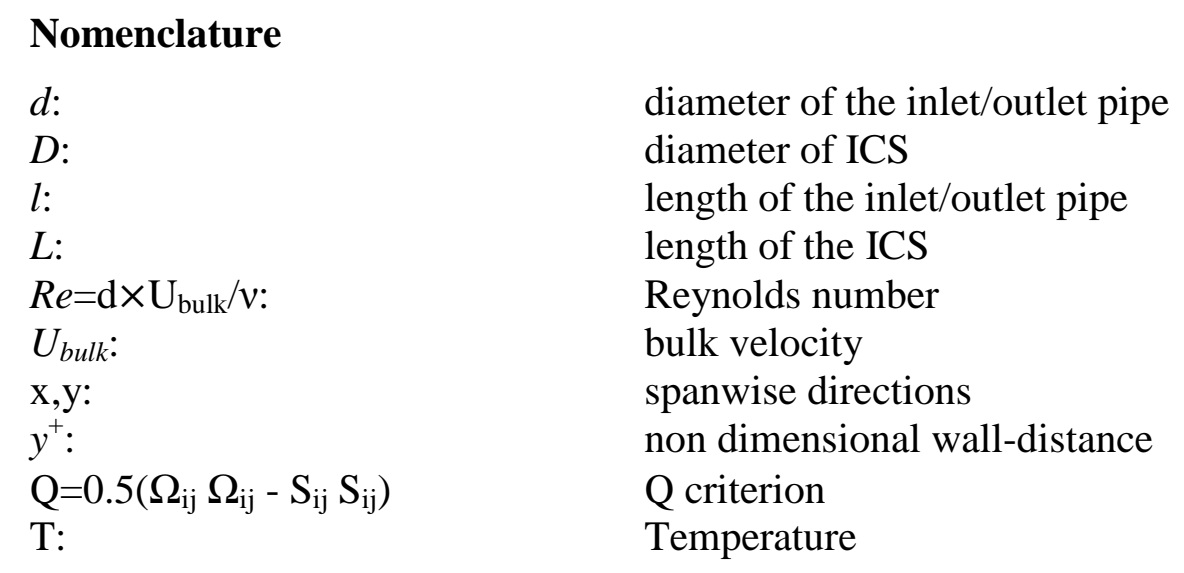

$d:$

$D:$

$l$ :

$L:$

$R e=\mathrm{d} \times \mathrm{U}_{\mathrm{bulk}} / v:$

$U_{\text {bulk: }}$ :

$\mathrm{x}, \mathrm{y}$ :

$y^{+}:$

$\mathrm{Q}=0.5\left(\Omega_{\mathrm{ij}} \Omega_{\mathrm{ij}}-\mathrm{S}_{\mathrm{ij}} \mathrm{S}_{\mathrm{ij}}\right)$

$\mathrm{T}$ :

\author{
diameter of the inlet/outlet pipe \\ diameter of ICS \\ length of the inlet/outlet pipe \\ length of the ICS \\ Reynolds number \\ bulk velocity \\ spanwise directions \\ non dimensional wall-distance \\ $\mathrm{Q}$ criterion \\ Temperature
}


Third International Conference on Applied Energy - 16-18 May 2011 - Perugia, Italy

$\mathrm{T}_{0}$ :

$\mathrm{T}_{\text {in }}$ :

$\mathrm{z}$ :

$v$ :

$v_{S G S}$ :

sub/super scripts:

*:
Initial temperature inside the chamber

Inlet temperature

streamwise direction.

molecular kinematic viscosity $\left[\mathrm{m}^{2} / \mathrm{s}\right]$

sub-grid scale kinematic viscosity $\left[\mathrm{m}^{2} / \mathrm{s}\right]$

normalised quantity

\section{References}

[1] Weiss W., Biermayr P., 2009, "Potential of solar thermal in Europe", European Solar Thermal Industry Federation (ESTIF), RESTMAC $6^{\text {th }}$ Framework EU founded project, http://www.solarthermalworld.org/node/878

[2] Kalogirou S.A., 2004, "Solar Thermal collectors and applications", Progress in Energy and Combustion Science, Vol. 30, pp. 231-295

[3] Hazami M., Kooli S., Lazaar M., Farhat A., Belghith A., 2005, "Performance of a solar storage collector" Desalination, Vol. 183, pp. 167-172

[4] Battisti R., Corrado A., 2005, "Environmental assessment of a solar thermal collectors with integrated water storage", Journal of Cleaner Production, Vol.13, pp.1295-1300

[5] Micangeli A., 2000, "Design and implementation of innovative systems for the exploitation of renewable sources in social conflict areas: desalination with heat recovery and hydro-electric energy production”, Sapienza University Doctoral Thesis, 2000.

[6] Hydrogen Centre web site, http://idrogenolazio.it/

[7] Ničeno B., Hanjalić K., (2005), 'Unstructured large-eddy- and conjugate heat transfer simulations of wall-bounded flows', Modeling and Simulation of Turbulent Heat Transfer, (Developments in Heat Transfer Series), M. Faghri and B. Sunden (Eds.), WIT Press, pp. 1-40.

[8] Delibra, G., Borello, D., Hanjalić, K., Rispoli, F., 2010. 'LES of flow and heat transfer in a channel with a staggered cylindrical pin matrix', Direct and Large-Eddy Simulation VII, V. Armenio, B. Geurts and J. Fröhlich, (Eds.), Springer, Vol. 13, 2010, ISBN: 978-90-481-3651-3

[9] Delibra, G., Borello, D., Hanjalić, K., Rispoli, F., 2009a. 'URANS of flow and endwall heat transfer in a pinned passage relevant to gas-turbine blade cooling', Int. J. Heat Fluid Flow, 30, pp. $549-560$

[10] Delibra, G., Borello, D., Hanjalić, K., and Rispoli, F. Vortex structures and heat transfer in a wall-bounded pin ma-trix: LES with a RANS wall-treatment. International Journal of Heat and Fluid Flow 31 (2010) 740-753.

[11] Borello D., Delibra G., Hanjalić K. and Rispoli F., 2009, "URANS and Hybrid LES/RANS Computations of Tip Leakage and Secondary Flows in Axial Compressor Cascade", Proceedings IMechE Part A: Journal of Power and Energy, Vol. 223, pp- 645-655.

[12] Germano M., Piomelli U., Moin P., Cabot W.H., 1991. 'A dynamic subgrid-scale eddy viscosity model', Physics of Fluids, 3 (7), pp. 1760-1765

[13] Lesieur M., Metais O., and Comte P., 2005, 'Large Eddy Simulations of turbulence', Cambridge University Press, New York, ISBN 0-521-78124-8 